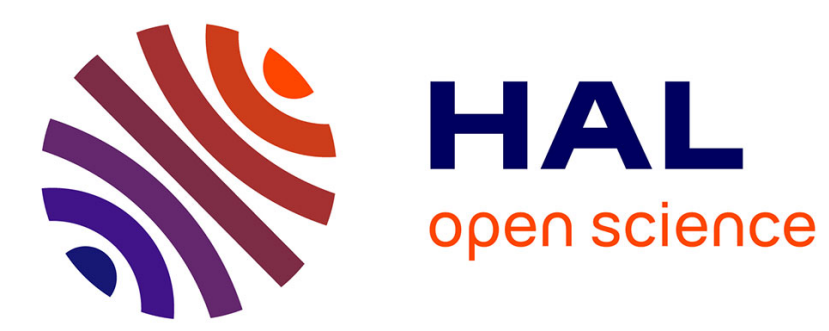

\title{
UPCONVERSION SPECTROSCOPY OF ERBIUM DOPED FLUORIDE CRYSTALS
}

\author{
J. Jouart, G. Mary
}

\section{To cite this version:}

J. Jouart, G. Mary. UPCONVERSION SPECTROSCOPY OF ERBIUM DOPED FLUORIDE CRYSTALS. Journal de Physique IV Proceedings, 1991, 01 (C7), pp.C7-335-C7-338. 10.1051/jp4:1991789 . jpa-00251032

\section{HAL Id: jpa-00251032 https://hal.science/jpa-00251032}

Submitted on 1 Jan 1991

HAL is a multi-disciplinary open access archive for the deposit and dissemination of scientific research documents, whether they are published or not. The documents may come from teaching and research institutions in France or abroad, or from public or private research centers.
L'archive ouverte pluridisciplinaire HAL, est destinée au dépôt et à la diffusion de documents scientifiques de niveau recherche, publiés ou non, émanant des établissements d'enseignement et de recherche français ou étrangers, des laboratoires publics ou privés. 


\title{
UPCONVERSION SPECTROSCOPY OF ERBIUM DOPED FLUORIDE CRYSTALS
}

\author{
J.P. JOUART and G. MARY \\ GRSM, Laboratoire d'Energétique et d'Optique, Université de Reims, F-51062 Reims cedex, France
}

\begin{abstract}
We study the red-to-green upconversion in $\mathrm{Er}^{3+}$ doped fluoride crystals. We show that the dominant upconversion process depends on the excitation wavelength: a two-step absorption between 631 and $634 \mathrm{~nm}$ and a two-ion interaction between 641 and $647 \mathrm{~nm}$ for an $\mathrm{Er}^{3+}$ doped cadmium fluoride at $77 \mathrm{~K}$. An efficient IR $(803 \mathrm{~nm})$-to-green upconversion via three-step absorption is also reported, for the first time, in $\mathrm{Er}^{3+}$ doped strontium fluoride at $300 \mathrm{~K}$. A selection of sites exhibiting two or three transitions which energetically coincide with an appropriate laser excitation wavelength could optimize the upconversion efficiencies.
\end{abstract}

1 - Introduction.

$\mathrm{Er}^{3+}$ upconverted fluorescence can appear following two processes: the two-step absorption proposed by Bloembergen [1] and the two-ion interaction observed by Auzel [2]. The two-step absorption becomes only efficient for laser excitation wavelengths which coincide [3] with that of the transitions between the excited states of the $\mathrm{Er}^{3+}$ ion. During the past few years, the two-step absorption has been successfully used to develop upconversion lasers [4]. We believe that the multi-step absorption efficiency can be optimized by improving the energy coincidence between the transitions and by selecting an appropriate excitation wavelength. Such a plan can be tested with the fluorite-type crystals $\left(\mathrm{MF}_{2}\right.$ with $\left.\mathrm{M}=\mathrm{Cd}, \mathrm{Ca}, \mathrm{Sr}, \mathrm{Ba}\right)$ in which, the $\mathrm{Er}^{3+}$ ions are distributed in a variety of non-equivalent sites.

\section{2 - Site multiplicity}

In the fluorite-type crystals, the $\mathrm{Er}^{3+}$ ion occupies a $\mathrm{M}^{2+}$ site, thus requiring a charge compensation. The symmetry and the strength of the crystal field acting on the $\mathrm{Er}^{3+}$ ion depend on the compensator and on its position relatively to the $\mathrm{Er}^{3+}$ ion. A large number of $\mathrm{Er}^{3+}$ sites has been observed. The crystal field splits the energy levels of the $\mathrm{Er}^{3+}$ free ion, into several components. Each distinct surroundings of the $\mathrm{Er}^{3+}$ ion gives rise to its own splitting, therefore to its own absorption or fluorescence spectrum. The $\mathrm{Er}^{3+}$ ions can also be paired. In $\mathrm{CdF}_{2}$ and $\mathrm{CaF}_{2}$, the pairs occur at $0.01 \mathrm{~mol} \%$ but their relative importance decreases as the size of the host cation increases across the $\mathrm{Cd}-\mathrm{Ca}-\mathrm{Sr}$-Ba series. Notice that the concentration of one site may be considerably enhanced through appropriate preparation.

As the energy coincidence behaves as a critical parameter, we expect large changes in the upconversion efficiency when the $\mathrm{Er}^{3+}$ surroundings is modified. This goal can be reached by the choice of a charge compensator [3]; another way consists in growing mixed crystals.

\section{3 - Experimental}

We use the selective laser excitation of the fluorescence to study the upconversion processes. A tunable laser beam is focused within the crystal. By adjusting the excitation wavelength, it is possible to excite only one erbium site at one time (optimum concentration $0.1 \mathrm{~mol} \%$ ). We select the fluorescence wavelength $\lambda_{\mathrm{f}}$ with a spectrometer and the excitation wavelength $\lambda_{e}$ with the tunable laser. The excitation spectra are obtained by monitoring the fluorescence as a function of the excitation wavelength. 
The experiments were performed at $77 \mathrm{~K}$, between 630 and $650 \mathrm{~nm}$ (by means of a Spectra-Physics 375 dye laser), on the one hand, on a $\mathrm{CdF}_{2}$ crystal double-doped with $0.1 \mathrm{~mol} \% \mathrm{Er}^{3+}$ and $0.1 \mathrm{~mol} \% \mathrm{Na}^{+}$in which most of the $\mathrm{Er}^{3+}$ ions are present in the form of Er single ions of $\mathrm{C}_{2 \mathrm{~V}}$ symmetry, on the other hand on a $\mathrm{CdF}_{2}$ crystal single-doped with $0.1 \mathrm{~mol} \% \mathrm{Er}$ in which the $\mathrm{Er}^{3+}$ ions are paired.

One $\mathrm{SrF}_{2}$ crystal doped with $1.3 \mathrm{~mol} \% \mathrm{Er}^{3+}$ has also been studied at $300 \mathrm{~K}$, following ${ }^{4} \mathrm{I}_{9 / 2}$ excitation around $800 \mathrm{~nm}$ with a Spectra Physics 3900 Ti sapphire laser.

\section{4 - Results and interpretation}

\section{4-1 Upconversion via two-step absorption}

We have studied the green emission from single $\mathrm{Er}^{3+}$ ions of $\mathrm{CdF}_{2}: 0.1 \mathrm{~mol} \% \mathrm{Er}^{3+}-0.1 \mathrm{~mol} \% \mathrm{Na}^{+}$ following their excitation by a red dye laser in a spectral range free from electronic levels. We establish that this fluorescence is as intense as that arising from $\mathrm{Er}^{3+}$ pairs. By comparing the excitation spectrum (fig 1) to the energy level structure, we show that the mechanism for exciting the ${ }^{4} S_{3 / 2}$ level is a two-photon process involving two sequential excitations (fig 2 ), with ${ }^{4} \mathrm{I}_{13 / 2}$ acting as the intermediate level. The upconversion efficiency is not very high because of a bad coincidence between the ground state absorption and the excited state absorption.

As the concentration increases $(1 \mathrm{~mol} \%)$, the sharp structure observed in the excitation spectrum is replaced by a large structure which coincide with the ${ }^{4} \mathrm{I}_{15 / 2}->4 \mathrm{~F}_{9 / 2}$ absorption spectrum, proving that the two-ion interaction prevails over the two-step absorption (fig 2) when the $\mathrm{Er}^{3+}$ concentration exceeds 1 mol \%.

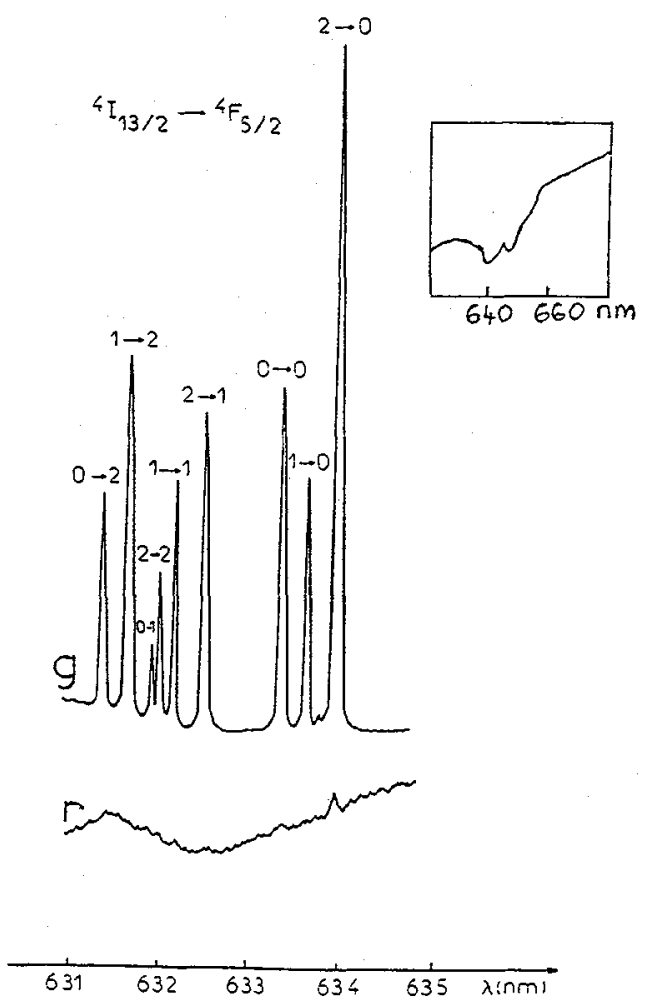

Fig 1 Red $(651.3 \mathrm{~nm})$ and green $(540.8 \mathrm{~nm})$ fluorescence excitation spectra of $\mathrm{CdF}_{2}: 0.1 \mathrm{~mol} \% \mathrm{Er}^{3+}-0.1 \mathrm{~mol} \% \mathrm{Na}^{+}$at $77 \mathrm{~K}$.

The insert shows the ${ }^{4} \mathrm{I}_{15 / 2} \rightarrow{ }^{4} \mathrm{~F}_{9 / 2}$ absorption spectrum at $300 \mathrm{~K}$.

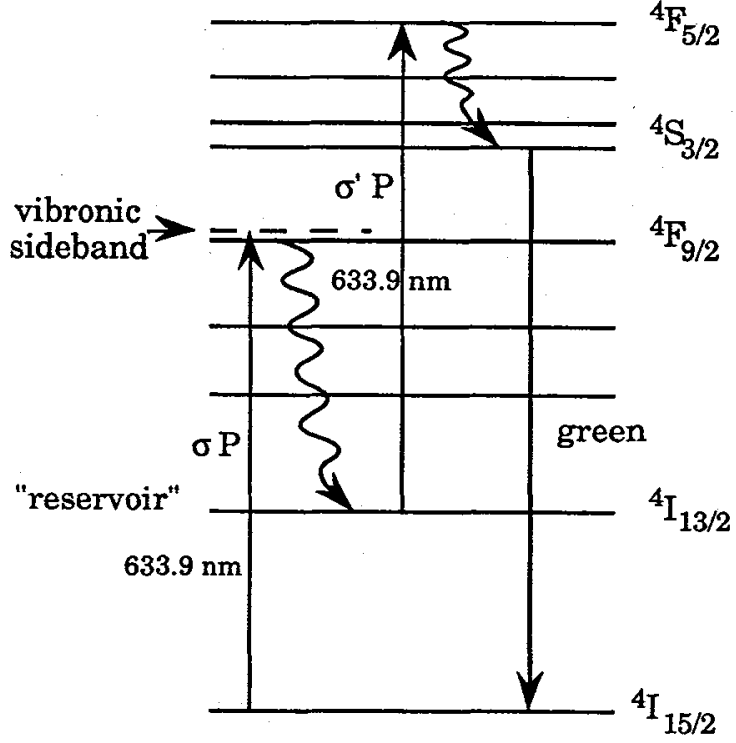

Fig 2 Red-to-green upconversion via two-step absorption 


\section{4-2 Upconversion via two-ion interaction}

The excitation spectrum for the green emission arising from $\mathrm{Er}^{3+}$ pairs of $\mathrm{CdF}_{2}: 0.1 \mathrm{~mol} \% \mathrm{Er}$ consists of many lines whose wavelengths are in resonance with the Stark components of the ${ }^{4} \mathrm{~F}_{9 / 2}$ multiplet. A narrowing of excitation spectrum is observed (fig 3), indicating that all the sites do not take part in the upconversion process via two-ion interaction.

Among the possible interactions, we believe that the interactions $\left({ }^{4} \mathrm{I}_{11 / 2},{ }^{4} \mathrm{~F}_{9 / 2}\right)$, described fig 4 , and $\left({ }^{4} \mathrm{I}_{11 / 2},{ }^{4} \mathrm{I}_{1 / 2}\right)$ prevail over all the others because of a large overlap between the involved transitions and of the irreversibility of transfers.

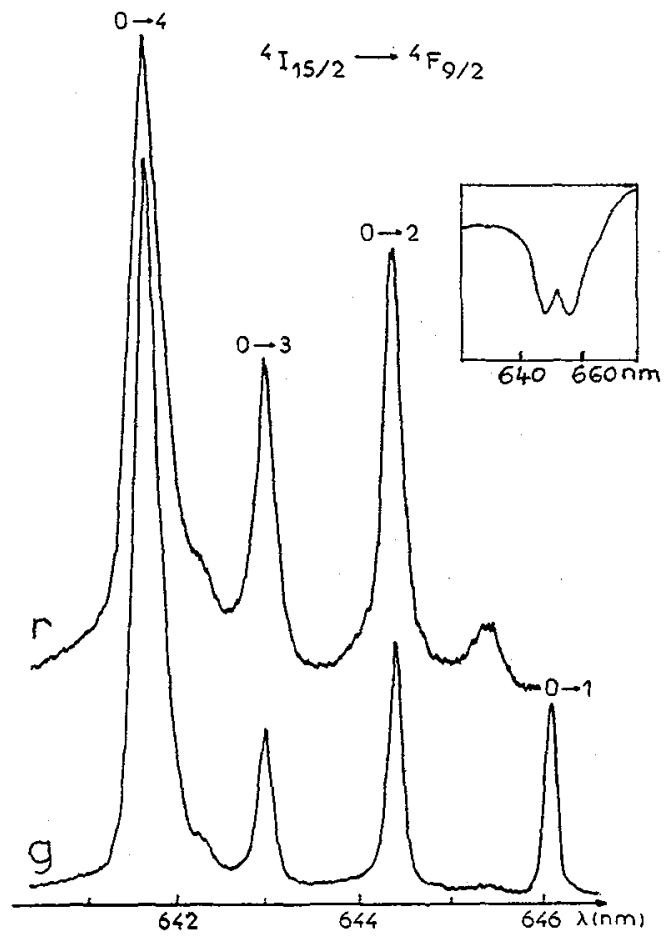

Fig 3 Red $(646.1 \mathrm{~nm})$ and green $(536.2 \mathrm{~nm})$ fluorescence excitation spectra of $\mathrm{CdF}_{2}: 0.1 \mathrm{~mol} \% \mathrm{Er}^{3+}$ at $77 \mathrm{~K}$.

The insert shows the ${ }^{4} \mathrm{I}_{15 / 2} \rightarrow{ }^{4} \mathrm{~F}_{9 / 2}$ absorption spectrum at $300 \mathrm{~K}$.

\section{4-3 Upconversion via three-step absorption at $803 \mathrm{~nm}$}

A strong green emission arising from $\mathrm{Er}^{3+}$ ions of $\mathrm{SrF}_{2}: 1.3 \mathrm{~mol} \% \mathrm{Er}^{3+}$ has been observed at $300 \mathrm{~K}$ under $803 \mathrm{~nm}$ excitation [5]. The cubic dependence of the green fluorescence intensity on the excitation power suggests a three-photon process. We propose a three-step absorption (fig 5) in agreement with all known experimental facts. The first step (GSA) excites most of the $\mathrm{Er}^{3+}$ ions on ${ }^{4} \mathrm{I}_{9 / 2}$ and then, through a rapid relaxation, on ${ }^{4} I_{11 / 2}$ and ${ }^{4} I_{13 / 2}$. The second step $\left(E S A_{1}\right)$ selects only the ions whose second transition is in resonance with the laser wavelength. It is the same with the third step $\left(E S A_{2}\right)$ which very efficiently contributes to the emptying of ${ }^{4} \mathrm{~F}_{9 / 2}$ (continuously fed back by $E S A_{1}$ ) and to the filling of ${ }^{4} S_{3 / 2}$, thus 
favouring the upconversion via three-step absorption compared with the two-step one. It is possible that this three-step absorption is assisted by an APTE effect [2] whose contribution could be estimated by decay measurements.

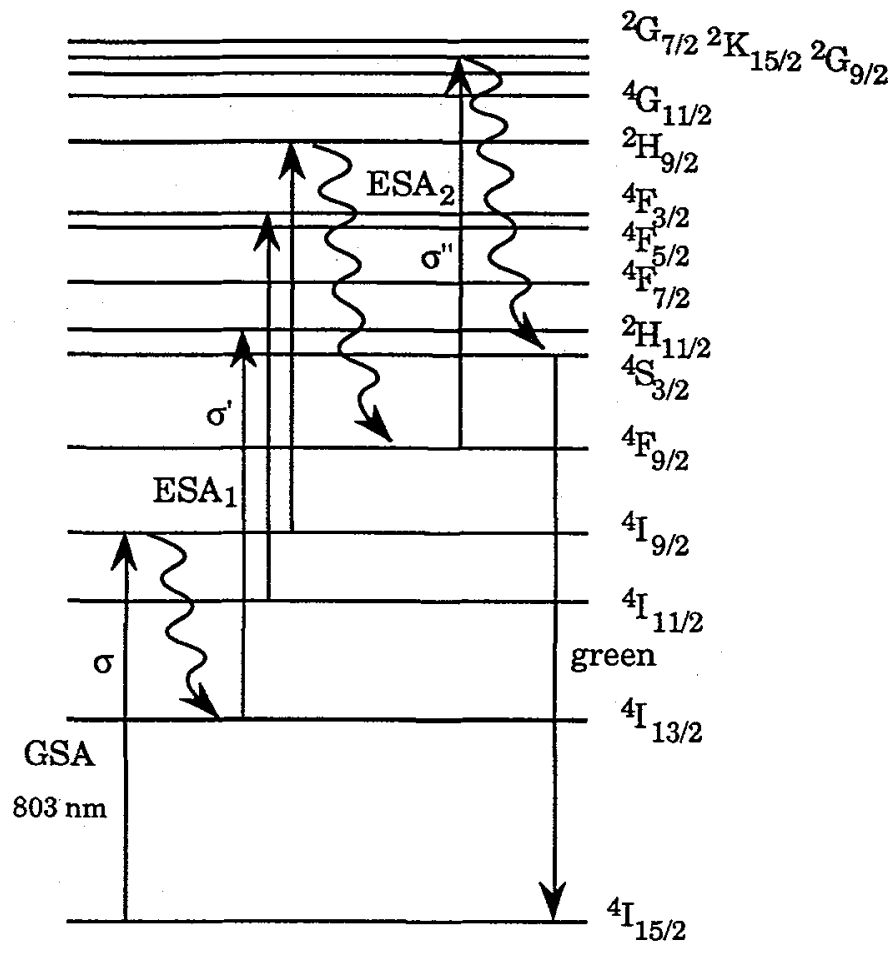

Fig 5 Upconversion via three-step absorption at $803 \mathrm{~nm}$ in $\mathrm{SrF}_{2}: 1.3 \mathrm{~mol} \% \mathrm{Er}^{3+}$ at $300 \mathrm{~K}$.

\section{5- Conclusion}

We have shown that the dominant upconversion process depends on the excitation wavelength. Concerning $\mathrm{CdF}_{2}: 0.1 \mathrm{~mol} \% \mathrm{Er}^{3+}$, a two-step absorption is observed between 631 and $634 \mathrm{~nm}$ on the high energy side of the ${ }^{4} \mathrm{I}_{15 / 2} \rightarrow{ }^{4} \mathrm{~F}_{9 / 2}$ transition while a two-ion interaction is observed between 641 and $647 \mathrm{~nm}$ (corresponding to the ${ }^{4} \mathrm{I}_{15 / 2} \rightarrow->{ }^{4} \mathrm{~F}_{9 / 2}$ transition). We have also observed an efficient $\mathrm{Er}^{3+}$ upconversion via three-step absorption in $\mathrm{SrF}_{2}: 1.3 \mathrm{~mol} \% \mathrm{Er}^{3+}$ at $300 \mathrm{~K}$. This three-step absorption involves two excited state absorptions, the first, $\mathrm{ESA}_{1}$, from ${ }^{4} \mathrm{I}_{13 / 2}$ (or ${ }^{4} \mathrm{I}_{11 / 2},{ }^{4} \mathrm{I}_{9 / 2}$ ), the second, $\mathrm{ESA}_{2}$, from ${ }^{4} \mathrm{~F}_{9 / 2}$. The high efficiency is probably due to a very good coincidence, around $803 \mathrm{~nm}$, between GSA, ESA 1 and $\mathrm{ESA}_{2}$.

\section{Acknowledgments}

We wish to thank E. Oomen of Philips Research Laboratories Eindhoven, for giving us access to his Ti sapphire tunable laser.

[1] N. Bloembergen, Phys. Rev. Lett. 2 (1959) 84

[2] F. Auzel, Proc. IEEE 61 (1973) 758

[3] J.P. Jouart, C. Bissieux and G. Mary, J. Phys. C : Solid State Phys. 20 (1987) 2019

[4] W. Lenth and R.M. Macfarlane, J. Lum. 45 (1990) 346

[5] J.P. Jouart and E. Oomen, to be published 